\title{
Stability Analysis of Gray-Scott Model in One-dimension
}

\author{
Abbas Y. Al-Bayati Saad A. Manaa Abdulghafor M. Al-Rozbayani \\ abdulghafor_rozbayani@uomosul.edu.iq \\ College of Computer Sciences and Mathematics, \\ University of Mosul, Iraq
}

Received on: 27/03/2007

Accepted on: 28/06/2007

\section{ABSTRACT}

In this Paper, we studied the stability analysis of steady state solutions of Gray-Scott Model in one-dimension using Fourier mode and we showed that the solutions are conditionally stable.

Keywords: Gray-Scott Model, stability analysis.

$$
\begin{aligned}
& \text { تحليل الاستقرارية لأنموذج گراي سكوت في بعد واحد }
\end{aligned}
$$

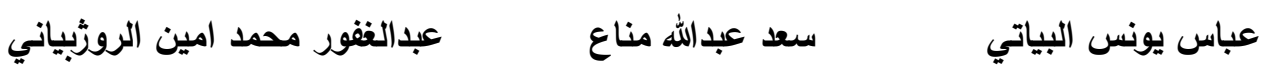

$$
\begin{aligned}
& \text { كلية علوم الحاسوب والرياضيات/جامعة الدوصل/العراق } \\
& \text { تاريخ قبول البحث:2007/06/28 } \\
& \text { تاريخ استلام البحث:2007/03/27 }
\end{aligned}
$$

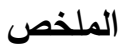

$$
\begin{aligned}
& \text { في هذا البحث درسنا الاستقرارية التحليلية للحلول اللازمنية لنموذج } \\
& \text { البعد الواحد باستخدام تحليل الأستقرارية من النمط فورير , وتبين لدينا أن الحلول مستقرة على نحو } \\
& \text { مشروط. } \\
& \text { الكلمات المفتاحية: أنموذج كر اي-سكوت, تحليل الاستقرارية. }
\end{aligned}
$$

\section{Introduction:}

A system of nature whatever that exists in stable state, in one sense or another, if small disturbance or change in the system, does not exist in time-dependent state in which the planets move about the sun in an orderly fashion. It is known that small additional celestial body is introduced into the system, and then the original state is stable to small disturbance. Similar equations of stability arise in every physical problem [5].

Saad and Bashar, studied the stability of a model of a fully developed laminar fluid flow in rectangular bend duct with secondary flow has been disturbed [9].

Sherratt [12] derived a condition for the wave train itself to be a stable solution, and present numerical evidence for a complex sequence of bifurcations in the unstable region of parameter space in reaction-diffusion equations.

Wan et. al [13] is concerned with several eigenvalue problems in the linear stability analysis of steady state morphogen gradients for several 
models of Drosophila wing imaginal discs including on not previously considered.

Gray and Scott [1] studied the simplest case, uniform temperatures and concentrations in the isothermal, and the simplest of the reaction schemes: (i) quadratic autocatalysis $(A+B \rightarrow 2 B)$; and (ii) cubic autocatalysis $(A+2 B \rightarrow 3 B)$. The catalyst $\mathrm{B}$ may be stable or have a finite lifetime. ( $B \rightarrow$ inert products). Allowing for this finite lifetime adds another dimension to our interest.

Scott [10] have considered the autocatalytic reactions: $A \rightarrow B$; rate $=\alpha u v^{n}, \mathrm{n}=0,1$ or 2 where $\mathrm{u}$ and $\mathrm{v}$ are the concentrations of $\mathrm{A}$ and $\mathrm{B}$, respectively. Interest centered mainly on irreversible system but for which the catalytic species not indefinitely stable, decaying instead by a rate proportional to its concentration $r$. In practice all chemical reactions are, to some extent, reversible. The present work investigates the effect of reversibility for the cases in which B does not decay.

Then Gray and Scott [2] studied the cubic autocatalytic reaction $(A+2 B \rightarrow 3 B)$ forms the basis for the simplest homogenous system to display "exotic" behavior, even under well-stirred, isothermal, open conditions (CSTR). They find multi stability, hysterias, extinction and anomalous relaxation times.

Scott [11] showed that the reactions that representations of nonlinear chemical feedback in an isothermal system are the proper type autocatalytic steps

$$
\begin{array}{lll}
\text { quadratic } u+v \rightarrow 2 v & \text { rat }=k_{1} u v \\
\text { cubic } \quad u+2 v \rightarrow 3 v & \text { rat }=k_{1} u^{2}
\end{array}
$$

are coupled with the diffusion of the reactants through a permeable boundary form and an external reservoir when the concentrations are held constant.

In this paper, we study the steady state solution and disturbance cases, when the wave amplitudes are constants of the system parameters.

The Gray-Scott scheme, which presents cubic-autocatalysis with linear catalyst decay, has been much considered, because of its multiple steadystate response and oscillatory solutions for review and descriptions of much of this work. The scheme is

$\mathrm{u}+2 \mathrm{v} \rightarrow 3 \mathrm{v}$, rate $=\beta \mathrm{uv}^{2}, \mathrm{v} \rightarrow \mathrm{w}$, rate $=\beta \gamma \mathrm{v}$,

Where the concentrations of the reactant and autocatalyst are $\mathrm{u}$ and $\mathrm{v}$, respectively. The parameters $\beta \square \square$ and $\gamma$ are rate constants. The catalyst is not stable, but undergoes a simple linear decay to a product $\mathrm{w}$. This allows a much wider variety of behavior in the system, than does the cubic reaction alone ([3], [4]). The nonlinear phenomena may be due to feedback through 
the detailed chemical mechanism or through departure from the isothermal state [1].

\section{The Mathematical Model}

The cubic-autocatalytic reaction with linear decay (1) is considered in a non dimensional reaction-diffusion cell are as follows:

$$
\begin{aligned}
& \mathrm{u}_{\mathrm{t}}=\mathrm{u}_{\mathrm{xx}}-\beta \mathrm{uv}^{2}, \\
& \mathrm{v}_{\mathrm{t}}=\mathrm{v}_{\mathrm{xx}}+\beta \mathrm{uv}^{2}-\beta \gamma \mathrm{v} \\
& \mathrm{u}_{\mathrm{x}}=\mathrm{v}_{\mathrm{x}}=0 \text { at } \mathrm{x}=0, \\
& \mathrm{u}=1, \mathrm{v}=\mathrm{v}_{0}, \text { at } \mathrm{x}=1 \text { and } \mathrm{t}=0
\end{aligned}
$$<smiles>CCCCC</smiles>

The system (2) is in non-dimensional form with the concentrations of the reactant and autocatalyst given by $u$ and $v$, respectively. The reactor has a permeable boundary at $\mathrm{x}=1$. Joined to a reservoir which contains $\mathrm{u}$ and $\mathrm{v}$ at constant concentrations. The boundary condition at $\mathrm{x}=0$ is a symmetry condition an identical reservoir is located at $\mathrm{x}=-1$. The system is characterized by three non-dimensional parameters. The ratio of the autocatalyst and reactant concentrations in the reservoir is $v_{0}$. The parameter $\beta$ is a measure of the importance of the reaction terms, compared with diffusion, while $\gamma$ is a measure of the importance of autocatalyst decay, compared with the cubic-reaction. The simplest way to adjust the nondimensional parameters experimentally is by changing the reservoir concentrations.

Other possibilities for varying the non-dimensional parameters include changing the diffusivity of the system or the length of the reactor. The diffusivity could be changed by adjusting the temperature or by the addition of otherwise inactive salts [7].

\section{Stability of the model:}

We study the analysis of non-dimensional Gray-Scott model in one dimension (2) using Fourier mode, and we assume that the value of concentrations of the reactant $u$ and autocalyst $v$, has the following form [5]:

$$
\left.\begin{array}{l}
\mathrm{u}(\mathrm{x}, \mathrm{t})=\mathrm{u}_{1}(\mathrm{x})+\mathrm{u}_{2}(\mathrm{x}, \mathrm{t}) \\
\mathrm{v}(\mathrm{x}, \mathrm{t})=\mathrm{v}_{1}(\mathrm{x})+\mathrm{v}_{2}(\mathrm{x}, \mathrm{t})
\end{array}\right\}
$$

where $\mathrm{u}_{1}$ and $\mathrm{v}_{1}$ denote the steady state case and $\mathrm{u}_{2}$ and $\mathrm{v}_{2}$ denote the disturbance case.

If we substitute (3) in (2) and neglecting the nonlinear terms, we get the following two systems (steady state system):

$$
\frac{\partial^{2} u_{1}}{\partial x^{2}}-\beta u_{1} v_{1}^{2}=0
$$

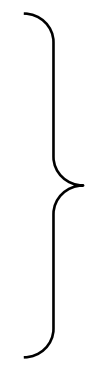


$\frac{\partial^{2} \mathrm{v}_{1}}{\partial \mathrm{x}^{2}}-\beta \mathrm{v}_{1}=0$

$\frac{\partial \mathrm{u}_{1}}{\partial \mathrm{x}}=\frac{\partial \mathrm{v}_{1}}{\partial \mathrm{x}}=0$ at $\mathrm{x}=0$

$\mathrm{u}_{1}=1, \mathrm{v}_{1}=\mathrm{v}_{\mathrm{o}}$ at $\mathrm{x}=1$ and $\mathrm{t}=0$

and the disturbance system has the form:

$\frac{\partial \mathrm{u}_{2}}{\partial \mathrm{t}}=\frac{\partial^{2} \mathrm{u}_{2}}{\partial \mathrm{x}^{2}}-\beta\left[2 \mathrm{u}_{1} \mathrm{v}_{1} \mathrm{v}_{2}+\mathrm{u}_{2} \mathrm{v}_{1}^{2}\right]$

$\frac{\partial \mathrm{v}_{2}}{\partial \mathrm{t}}=\frac{\partial^{2} \mathrm{v}_{2}}{\partial \mathrm{x}^{2}}+\beta\left[2 \mathrm{u}_{1} \mathrm{v}_{1} \mathrm{v}_{2}+\mathrm{u}_{2} \mathrm{v}_{1}^{2}\right]-\beta \gamma \mathrm{v}_{2}$

$\frac{\partial \mathrm{u}_{2}}{\partial \mathrm{x}}=\frac{\partial \mathrm{v}_{2}}{\partial \mathrm{x}}=0$ at $\mathrm{x}=0$

$\mathrm{u}_{2}=1, \mathrm{v}_{2}=\mathrm{v}_{\mathrm{o}}$ at $\mathrm{x}=1$ and $\mathrm{t}=0$

\section{Steady state case solutions:}

For treatment of stability of the model, first the whole solution of the steady state case, we solve equation ( $4 \mathrm{~b})$ for $\mathrm{v}_{1}$ we get:

$\mathrm{v}_{1}(\mathrm{x})=\frac{\mathrm{v}_{0}}{\mathrm{~S}}\left[\mathrm{e}^{\sqrt{\beta \gamma} \mathrm{x}}+\mathrm{e}^{-\sqrt{\beta \gamma} \mathrm{x}}\right]$,

where $\mathrm{S}=\left[\mathrm{e}^{\sqrt{\beta \gamma}}+\mathrm{e}^{-\sqrt{\beta \gamma}}\right]$.

For the boundary condition $(4 \mathrm{~d})$ we get:

$\mathrm{v}_{1}(\mathrm{x})=\mathrm{v}_{0} \quad$ at $\quad \mathrm{x}=1$,

then we can solve equation (4a), to get

$\mathrm{u}_{1}(\mathrm{x})=\mathrm{C}_{0}\left(1+2 \mathrm{ax}^{2}+\frac{8 \mathrm{a}^{2}+\mathrm{b}^{2} \mathrm{a}}{12} \mathrm{x}^{4}+\cdots\right)$,

where $\mathrm{C}_{0}=1 /\left(1+2 \mathrm{a}+\frac{8 \mathrm{a}^{2}+\mathrm{b}^{2} \mathrm{a}}{12}+\cdots\right)$

$\mathrm{a}=\beta \mathrm{q}_{0}, \quad \mathrm{q}_{0}=\frac{\mathrm{v}_{0}^{2}}{\mathrm{~S}^{2}}, \mathrm{~b}=2 \sqrt{\beta \gamma}, \quad \mathrm{S}=\left[\mathrm{e}^{\sqrt{\beta \gamma}}+\mathrm{e}^{-\sqrt{\beta \gamma}}\right]$,

and thus from boundary condition (4d) we get:

$u_{1}(x)=1 \quad$ at $\quad x=1$

\section{Disturbance case:}

When the wave amplitudes are constants, stability analysis has been recently studied by numerous authors [6] and it is of great interest because of the growing industrial importance.

Assume that $\mathrm{u}_{2}$ and $\mathrm{v}_{2}$ has the following form [8]: 
$\left[\begin{array}{l}u_{2}(x, t) \\ v_{2}(x, t)\end{array}\right]=\left[\begin{array}{l}y_{1} \\ y_{2}\end{array}\right] e^{i k(x-c t)}$

where $\left(c=c_{1}+i c_{2}\right)$, is an eigenvalue represent the speed of the wave, $\mathrm{y}_{1}$ and $\mathrm{y}_{2}$ are constants and $\mathrm{k}$ is the wave number. The problem is stable if the linearized equation corresponds to eigenvalue $\mathrm{c}$ with negative part $\left(c_{2}<0\right)$ for presented configurations [5].

Now, if we substitute (7) in the equations (5a), we shall get:

$-i k c y_{1} e^{i k(x-c t)}=-k^{2} y_{1} e^{i k(x-c t)}-2 \beta u_{1} v_{1} y_{2} e^{i k(x-c t)}-\beta v_{1}^{2} y_{1} e^{i k(x-c t)}$

i.e. multiply both sides by $\mathrm{e}^{-\mathrm{ik}(\mathrm{x}-\mathrm{ct})}$ we get:

$-i k c y_{1}=-k^{2} y_{1}-2 \beta u_{1} v_{1} y_{2}-\beta v_{1}^{2} y_{1}$

$-\mathrm{ik}\left(\mathrm{c}_{1}+\mathrm{ic}_{2}\right) \mathrm{y}_{1}=-\mathrm{k}^{2} \mathrm{y}_{1}-2 \beta \mathrm{u}_{1} \mathrm{v}_{1} \mathrm{y}_{2}-\beta \mathrm{v}_{1}^{2} \mathrm{y}_{1}$

$-\mathrm{ikc}_{1} \mathrm{y}_{1}=0 \Rightarrow \mathrm{c}_{1}=0$

$\mathrm{kc}_{2} \mathrm{y}_{1}=-\mathrm{k}^{2} \mathrm{y}_{1}-2 \beta \mathrm{u}_{1} \mathrm{v}_{1} \mathrm{y}_{2}-\beta \mathrm{v}_{1}^{2} \mathrm{y}_{1}$

$c_{2}=\frac{-\left(k^{2}+2 \beta u_{1} v_{1} \frac{y_{2}}{y_{1}}+\beta v_{1}^{2}\right)}{k}$

where $\mathrm{y}_{1}, \mathrm{y}_{2}, \mathrm{k}, \beta$ are positive real number.

So if $\left(\mathrm{k}^{2}+2 \beta \mathrm{u}_{1} \mathrm{v}_{1} \frac{\mathrm{y}_{2}}{\mathrm{y}_{1}}+\beta \mathrm{v}_{1}^{2}\right)<0$ and $\mathrm{u}_{1}$ and $\mathrm{v}_{1}$ have different signs then we have $c_{2}>0$ and thus the system is unstable.

Also if $\left(\mathrm{k}^{2}+2 \beta \mathrm{u}_{1} \mathrm{v}_{1} \frac{\mathrm{y}_{2}}{\mathrm{y}_{1}}+\beta \mathrm{v}_{1}^{2}\right)>0$ and $\mathrm{u}_{1}$ and $\mathrm{v}_{1}$ have the same signs then we have $c_{2}<0$ which implies that the system is stable.

If $c_{2}=0$ then we can get the neutral curve.

Now if we substitute (7) in equation (5b) we shall get

$-\mathrm{ikcy}{ }_{2} \mathrm{e}^{\mathrm{ik}(\mathrm{x}-\mathrm{ct})}=-\mathrm{k}^{2} \mathrm{y}_{2} \mathrm{e}^{\mathrm{ik}(\mathrm{x}-\mathrm{ct})}+2 \beta \mathrm{u}_{1} \mathrm{v}_{1} \mathrm{y}_{2} \mathrm{e}^{\mathrm{ik}(\mathrm{x}-\mathrm{ct})}+\beta \mathrm{v}_{1}^{2} \mathrm{y}_{1} \mathrm{e}^{\mathrm{ik}(\mathrm{x}-\mathrm{ct})}-\beta \gamma \mathrm{y}_{2} \mathrm{e}^{\mathrm{ik}(\mathrm{x}-\mathrm{ct})}$

also if we multiply both sides by $\mathrm{e}^{-\mathrm{ik}(\mathrm{x}-\mathrm{ct})}$ we get

$-i \mathrm{k}\left(\mathrm{c}_{1}+\mathrm{ic}_{2}\right) \mathrm{y}_{2}=-\mathrm{k}^{2} \mathrm{y}_{2}+2 \beta \mathrm{u}_{1} \mathrm{v}_{1} \mathrm{y}_{2}+\beta \mathrm{v}_{1}^{2} \mathrm{y}_{1}-\beta \gamma \mathrm{y}_{2}$

$-\mathrm{ikc}_{1} \mathrm{y}_{2}=0 \Rightarrow \mathrm{c}_{1}=0$

$\mathrm{kc}_{2} \mathrm{y}_{2}=-\mathrm{k}^{2} \mathrm{y}_{2}+2 \beta \mathrm{u}_{1} \mathrm{v}_{1} \mathrm{y}_{2}+\beta \mathrm{v}_{1}^{2} \mathrm{y}_{1}-\beta \gamma \quad \mathrm{y}_{2}$

$c_{2}=\frac{-k^{2}+2 \beta u_{1} v_{1}+\beta v_{1}^{2} \frac{y_{2}}{y_{1}}-\beta \gamma}{k}$

thus according to the above discussion we have three cases: 
if $c_{2}>0$ then the system is unstable.

if $\mathrm{c}_{2}<0$ then the system is stable.

if $c_{2}=0$ then get the neutral curve.

Then the neutral stability curve shows that in figure (1) when $c_{2}<0$ then $\mathrm{k}=\sqrt{2 \beta \mathrm{u}_{1} \mathrm{v}_{1}+\beta \mathrm{v}_{1}^{2} \frac{\mathrm{y}_{2}}{\mathrm{y}_{1}}-\beta \gamma}$ for the steady state solution $\mathrm{v}_{1}$ is defined in eq.(6) with $\mathrm{v}_{0}=0.1$ and $\mathrm{u}_{1}=1$ when $\beta=30, \gamma=0.05, \mathrm{yl}=\mathrm{y} 2=1$ and $0 \leq \mathrm{x} \leq 1$.

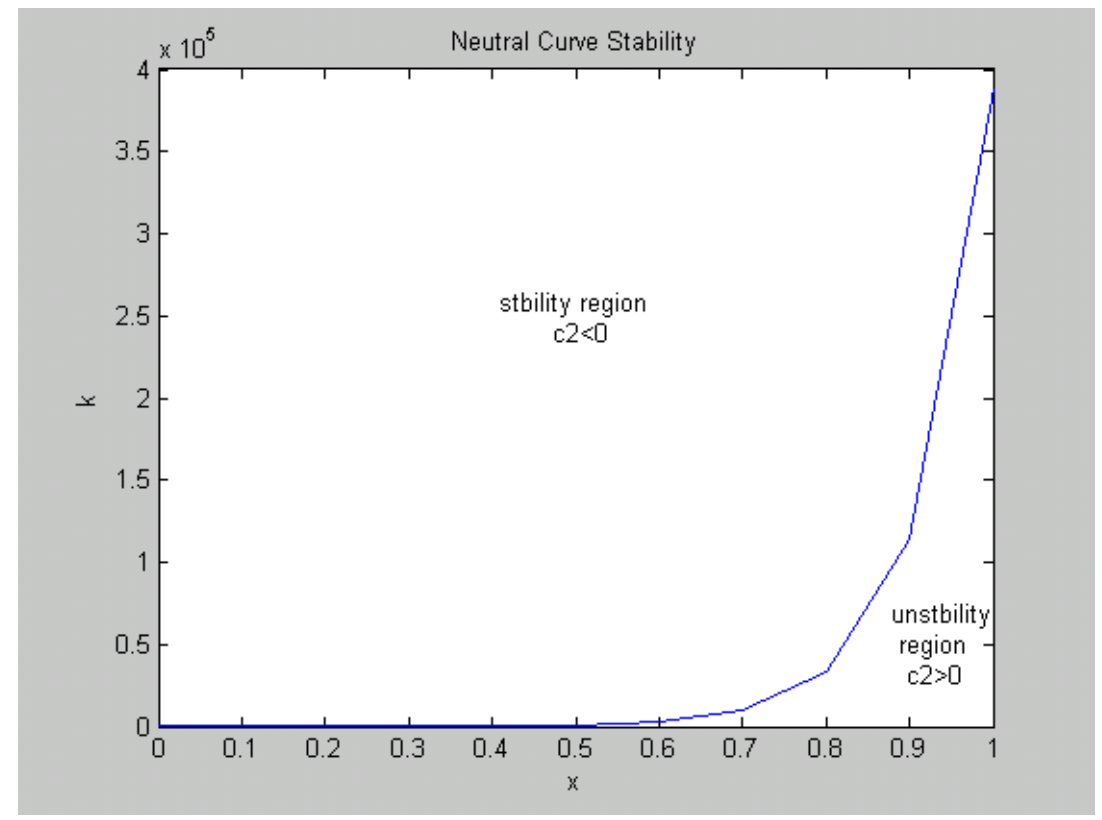

Figure (1) the neutral stability curve

\section{CONCLUSION}

From stability analysis of steady state solutions we conclude that the system is stable when $\mathrm{c}_{2}<0$. 


\section{REFERENCES}

[1] Gray, P. and Scott, S. k., (1983), "Autocatalytic Reactions in the Isothermal, Continuous Stirred Tank Reactor, Isolas and other Forms of Multistability", Chemical Engineering Science Vol.38, No.1, Pp.29-43.

[2] Gray, P. and Scott, S. K., (1984), "Autocatalytic Reactions in the Isothermal, Continuous Stirred Tank Reactor, Oscillations and Instabilities in the System $\mathrm{A}=2 \mathrm{~B} \rightarrow 3 \mathrm{~B} ; \mathrm{B} \rightarrow \mathrm{C}$ “, Chemical Engineering Science Vol. 39, No.6, Pp.1087-1097.

[3] Gray, P. and Scott, S.K. , (1990), "Chemical oscillations and instabilities: nonlinear chemical kinetics", Oxford University Press.

[4] Gray, P., (1988), "Instabilities and Oscillations in Chemical Reactions in Closed and Open Systems", Proc. R. Soc. Lond., A 415, 1-34.

[5] Logan, J.D., (1987), “Applied Mathematics”, John Wiley and Sons.

[6] Manaa, S. A. and Moheemeed, M. A., (2005), "Stability Analysis for Steady State Solutions of Huxley Equation", Raf. J. of Com. \& Math's. vol.2, No.1, Pp.669-84.

[7] Marchant, T. R., (2002), "Cubic Autocatalytic Reaction-Diffusion Equations : Semi-Analytical Solution", Proc. R. Soc Lond., A 458, Pp.1-16.

[8] Rutayna, J., (2004), "Analysis of Thin Liquid Films", Ph.D. Thesis, University of Mosul.

[9] Saad, A. Manaa and Bashar M. Ibrahim, (2004), "Stability Analysis for Fully Developed Laminar Fluid Flow in a Rectangular Bend with Secondary Flow”, Raf. Jour., Vol. 15, No. 1, pp. 146-152.

[10] Scott, S. K., (1983), "Reversible Autocatalytic Reactions in an Isothermal CSTR: Multiplicity, Stability and Relaxation Times", Chemical Engineering Science Vol.38, No.10, Pp.1701-1708.

[11] Scott, S. K., (1987), "Isolas, Mushroms and Oscillations in Isothermal, Autocatalytic Reaction-Diffusion Equations", Chemical Engineering Science Vol.42, No.2, Pp.307-315.

[12] Sherratt, J.A., (1995), "Unstable Wave Trains and Chaotic Wakes in Reaction-Diffusion Systems of $\lambda$-w Type", Physical D 82, 165-179.

[13] Wan, F.Y.M., Lou, Y. and Nie, Q. (2004), "Nonlinear Eigenvalue Problems in the Stability Analysis of Morphogen Gradients", Massachusetts Institute of Technology, Studies in Applied Mathematics 113: 183-215. 